\title{
JURISPRUDENCIA DE LA CORTE INTERAMERICANA DE DERECHOS HUMANOS: CASO ROSENDO RADILLA PACHECO
}

\author{
JURISPRUDÊNCIA DA CORTE INTERAMERICANA DE DIREITOS HUMANOS: \\ CASO ROSENDO RADILLA PACHECO
}

\section{JURISPRUDENCE OF THE INTER-AMERICAN COURT OF HUMAN RIGHTS: CASE ROSENDO RADILLA PACHECO}

\author{
ALFONSO JAIME MARTínEZ LAZCANO \\ Investigador Nacional del Sistema Nacional de Investigadores Conacyt, Doctor en Derecho Público, Profesor e \\ Investigador de la Universidad Autónoma de Chiapas y profesor honorario de la Facultad de Derecho de la Universidad \\ Nacional Autónoma de México. (Chiapas, México) \\ https://orcid.org/0000-0003-0367-4716 / alfonso.martinez@unach.mx
}

\begin{abstract}
RESUMEN
El Caso Rosendo Radilla Pacheco ocasionó una revolución jurídica en el ámbito interno de México al transformar la forma de como ahora todos los jueces nacionales deben interpretar y aplicar el derecho; modificar la práctica judicial de un control concentrado de constitucionalidad a difuso; así como agregar la obligación de ejercer el control difuso de convencionalidad de oficio, pero además, a través de la jurisprudencia convencional limitar de manera tajante a la jurisdicción militar para conocer procesos que tengan relación con violación de derechos humanos.
\end{abstract}

Palabras clave: Casos; Corte Interamericana; derechos humanos; juez natural; jurisdicción militar; México.

\section{RESUMO}

O caso Rosendo Radilla Pacheco gerou uma revolução jurídica no âmbito interno do México ao transformar a forma como a partir de agora todos os juízes devem interpretar e aplicar o Direito; modificar a prática judicial de um controle concentrado de constitucionalidade ao difuso; assim como agregar a obrigação de exercer o controle difuso de convencionalidade de ofício e, além disso, através da jurisprudência convencional, limitar de maneira taxativa a jurisdição militar para conhecer processos que tenham relação com a violação dos direitos humanos.

Palavras-chave: Casos; Corte Interamericana; direitos humanos; juiz natural; jurisdição militar; México.

\section{ABSTRACT}

The Rosendo Radilla Pacheco case brought about a legal revolution in Mexico's internal sphere, transforming the way in which all national judges must now interpret and apply the law; modify the judicial practice of a concentrated control of constitutionality to a diffuse one; as well as adding the obligation to exercise diffuse control of conventionality ex officio, and, besides that, through conventional jurisprudence, to limit in a taxactive way the military jurisdiction in order to know processes that are related to human rights violations.

Keywords: Cases; Inter-American Court; human rights; natural judge; military jurisdiction; Mexico.

\section{SUMARIO}

INTRODUCCIÓN; 1 JURISPRUDENCIA; 1.1 Corte Interamericana de Derechos Humanos; 2 JUEZ NATURAL; 2.1 Debido processo; 2.2 Jurisdicción castrense; 2.2.1 Disciplina militar; 2.2.2 Juez natural integral; 2.2.3 Juez natural integral. Disciplina militar; 2.2.4 Juez natural. Sanción a los responsables. Disciplina militar; 3 RECURSO EFICAZ; 3.1 Características; 3.1.1 ¿Qué significa que el recurso sea 
sencillo?; 3.1.2 ¿Qué significa que el recurso sea eficaz?; 3.1.3 Recurso como derecho a la defensa; 3.2 Recurso eficaz e idóneo; 3.3 Cumplimiento de la sentencia; 4 CONTROL DIFUSO DE CONVENCIONALIDAD; 4.1 Impacto ante la Suprema Corte de Justicia de la Nación; 4.1.1 Referencias; 4.2 Control de convencionalidad. Efecto útil; CONCLUSIÓN; REFERENCIAS.

\section{INTRODUCCIÓN}

La sentencia de fondo del Caso Rosendo Radilla Pacheco (RRP) emitida por la Corte Interamericana de Derechos Humanos (Corte IDH) generó una serie de interesantes jurisprudencias relacionadas especialmente con la justicia miliar: el juez natural, la disciplina militar; la exigencia de establecer en las normas procesales un recurso eficaz; sujetar las actuaciones del Estado al concepto del plazo razonable; la distinción entre las víctimas directas e indirectas; la forma de reparación integral; la violación de la integridad personal de familiares; sufrimiento de las víctimas; la integridad personal; el tipo de desaparición forzada de personas como ilícito continuo o permanente; el acceso al expediente durante la investigación; la obtención de copias de la averiguación previa por parte de las víctimas; el derecho a la verdad; el efecto útil de las normas convencionales; el control difuso de convencionalidad; el deber del Estado de realizar investigaciones serias y efectivas, entre otras para procesar y sancionar a los responsables de la violación de derechos humanos para combatir a la impunidad.

Este trabajo analiza el principio del juez natural y su relación con otros derechos procesales, el recurso sencillo y eficaz y el control difuso de convencionalidad producto de la sentencia del Caso RRP.

\section{JURISPRUDENCIA}

La jurisprudencia es la interpretación jurídica de las normas, principios y directrices que realizan los órganos jurisdiccionales facultados para emitir criterios que trascienden al caso concreto y vinculan a los tribunales de menor jerarquía a ser observada en la solución de controversias.

Ulpiano definió a la jurisprudencia como la ciencia del justo y del injusto.

Etimológicamente es un cultismo que proviene del latín jurisprudentia, que deriva de jus (que significa derecho) y prudentia (previsión o conocimiento) las que conjuntamente pueden entenderse como: la prudencia de lo justo. También 
se ha considerado que proviene de prudens, prudentis, que literalmente significa "sabio, conocedor). ${ }^{1}$

\subsection{Corte Interamericana de Derechos Humanos}

En cada caso la Corte IDH emite una serie de criterios o parámetros obligatorios para todos los Estados Parte del SIDH, que puede verse desde las siguientes perspectivas:

a) La jurisprudencia convencional es fuente del derecho nacional;

b) La jurisprudencia convencional es emitida en las sentencias, en las medidas provisionales y en las decisiones de supervisión de cumplimiento;

d) La jurisprudencia convencional está conformada por los argumentos expuestos en la parte considerativa de la resolución que sirven para fundamentarla, y

e) La jurisprudencia es obligatoria para todos los Estados Parte del SIDH.

La jurisprudencia resultante del trabajo de la Corte IDH debe ser tomada en cuenta por todos los Estados que forman parte del SIDH. En este sentido, la jurisprudencia debe entenderse como la interpretación que hace la Corte IDH respecto de la $\mathrm{CADH}$, así como los protocolos adicionales y de aquellos instrumentos de carácter internacional, relacionados con los DH que forman parte del Corpus luris. ${ }^{2}$

La jurisprudencia convencional de manera integral (incluye todos los fundamentos, motivaciones, alcances su ratio decidendi, la parte resolutiva o dispositiva). ${ }^{3}$

\section{JUEZ NATURAL}

El principio del juez natural se refiere a la competencia, a la facultad de los órganos del Estado para realizar determinadas funciones previstas y delimitadas en la ley. (Principio de legalidad).

La palabra competencia: "encuentra su raíz etimológica en las voces latinas competentía, a competens, entis, relación, proposición, aptitud, apto, competente,

\footnotetext{
${ }^{1}$ ROSALES GUERRERO, E. G., Estudio sistemático de la jurisprudencia, SCJN, México, 2005, p.44.

${ }^{2}$ MARTÍNEZ LAZCANO, A. J. y CUBIDES CÁRDENAS, A. J, Influencia de la Corte Interamericana de Derechos Humanos y el control de convencionalidad: Análisis de dos casos paradigmáticos. En Eficacia del Sistema Interamericano de Derechos Humanos, Colección Jus Universidad Católica de Colombia, Bogotá, 2015, p. 103.

${ }^{3}$ Corte IDH. Supervisión del Caso Gelman Vs. Uruguay, Corte IDH, 20 de marzo de 2013, párrafo 102.
} 
conveniencia. En castellano se usan como sinónimos los vocablos: aptitud, habilidad, capacidad, suficiencia, disposición". ${ }^{4}$ Del verbo competer, que le corresponde.

\subsection{Debido processo}

El debido proceso involucra no sólo un continuo acatamiento a las reglas y principios de carácter procesal, también implica cumplir con determinados valores, ya que sin su observancia el proceso es nulo.

Debido Proceso (no solamente al seguimiento de ciertas formas, sino principalmente a la plena vigencia de los valores que se encuentran detrás o buscan protegerse con este concepto), y, por qué no decirlo, de la visión del Derecho y lo jurídico que se maneja en Estados Unidos, la cual como todos sabemos no se limita a las prescripciones hechas por algún legislador. ${ }^{5}$

El juez natural es un ingrediente fundamental del acceso a la justicia, se relaciona con el derecho humano al debido proceso, implica que todo órgano jurisdiccional para conocer de un asunto debe necesariamente qestar facultado para ello, es decir, ser competente (presupuesto procesal ${ }^{6}$ ), durante todo el procedimiento (tanto en primera como en segunda instancia), aunado a que el tribunal debe estar constituido previamente a los hechos materia de la litis, incluir en las normas del procedimiento un recurso sencillo y eficaz para impugnar las decisiones judiciales, que la forma de juzgar sea pública aunado al principio de contradicción, que sus decisiones se funden en los fines de la norma sustantiva, que impere la razón y que las partes sean atendidas con equidad, lo cual en su conjunto son elementos idóneos para garantizar la imparcialidad e independencia judicial.

Así, "el debido proceso y el juez natural, como parte integrante de este, constituyen derechos básicos en la protección del ser humano". ${ }^{7}$

\footnotetext{
${ }^{4}$ FLORES-GARCÍA, F., Jurisdicción. Diccionario Jurídico Mexicano, Porrúa, México, 1992, p. 542.

5 FERNÁNDEZ GONZÁLEZ, Miguel Ángel, Derecho a la jurisdicción y debido proceso. Estudios Constitucionales [en linea] 2004, 2. Disponible en:<http://www.redalyc.org/articulo.oa?id=82020103> . Acesso em: 15 maio 2017. ISSN 0718-0195.

${ }^{6}$ Presupuestos procesales, de acuerdo con Couture, citado por Ovalle Favela, son: "Aquellos antecedentes necesarios para que el juicio tenga existencia jurídica y validez formal." (FAVELA, Ovalle. Derecho Procesal Civil, 1995, pág. 71). En resumen, son los requisitos indispensables para que se integre el proceso y sea factible emitir la sentencia que entre al fondo del asunto.

${ }^{7}$ QUISPE REMÓN , F., El derecho al juez natural -como derecho humano- y los tribunales militares en Colombia, Eunomía. Revista en Cultura de la Legalidad, 2013, p.119.
} 
El artículo 8, punto 1, denominado de las Garantías Judiciales al referirse a los derechos procesales destaca la calidad de los órganos jurisdiccionales de ser competente:

Toda persona tiene derecho a ser oída, con las debidas garantías y dentro de un plazo razonable, por un juez o tribunal competente, independiente e imparcial, establecido con anterioridad por la ley, en la sustanciación de cualquier acusación penal formulada contra ella, o para la determinación de sus derechos y obligaciones de orden civil, laboral, fiscal o de cualquier otro carácter.

\subsection{Jurisdicción castrense}

La jurisdicción es la potestad del Estado para aplicar las disposiciones jurídicas a las pretensiones planteadas por las partes en un proceso.

La palabra jurisdicción tiene su raigambre latina "proviene de jurisdictio-onis, poder o autoridad que se tiene para gobernar o poner en ejecución las leyes, o para aplicarlas en juicio (Becerra Bautista). 0 bien, si se atiende a las voces latinas jus, derecho, recto, y dicere, proclamar, declarar, decir, significa proclamar" derecho. $^{8}$

La jurisdicción castrense está limitada a resolver cuestiones propias de la disciplina militar y a los bienes del ámbito castrense, ajena a cualquier tipo de proceso donde la litis ventile la violación a derechos humanos, sea la parte activa o pasiva, un civil o militar, la víctima o victimario, en este supuesto la competencia corresponde exclusivamente a los tribunales civiles, tampoco la policía militar debe intervenir en las investigaciones de ésta índole, las cuales deben ser diligentes, serias y eficaces para lograr la identificación de los posibles responsables, procesarlos y dictar eventual sanción que corresponda.

\subsubsection{Disciplina militar}

La idea de disciplina versa sobre el control de la conducta de alguien, pero también a la acción de educar, el Diccionario de la Real Academia de la Lengua Española, define: Instruir, enseñar a alguien su profesión, dándole lecciones, ahora cuanto estas enseñanzas se refieren a lo militar, vocablo que el mismo Diccionario señala, entre sus acepciones el: "Servir en la guerra", así la disciplina militar es la preparación para el combate, el aprender a atacar y a

${ }^{8}$ FLORES-GARCÍA, F., op. cit., p.1884. 
defenderse, se podría sintetizar en la tarea de convertir a un hombre o mujer en atleta para la beligerancia.

Por otra parte, la idea de la milicia se relaciona con la obediencia de los mandos superiores sin "margen de apreciación", frases como "las órdenes no se discuten", de hecho el artículo 301 del Código de Justicia Militar (CJM) dispone:

Comete el delito de desobediencia el que no ejecuta o respeta una orden del superior, la modifica de propia autoridad o se extralimita al ejecutarla. Lo anterior se entiende salvo el caso de la necesidad impuesta al inferior, para proceder como fuere conveniente, por circunstancias imprevistas que puedan constituir un peligro justificado, para la fuerza de que dependa o que tuviese a sus órdenes.

La desobediencia puede cometerse dentro y fuera del servicio.

La sentencia del caso RRP ocasionó sin duda la adición del segundo párrafo al artículo 37 del CJM, mediante decreto publicado en el Diario Oficial de la Federación el 13 de junio de 2014:

\begin{abstract}
Cuando de las diligencias practicadas en la investigación de un delito se desprenda que este no atenta contra la disciplina militar, en términos del artículo $57^{9}$ de este Código, inmediatamente y bajo su más estricta responsabilidad del Ministerio Público Militar deberá remitir la indagatoria a la autoridad civil que corresponda, absteniéndose de ordenar ulteriores actuaciones, sin perjuicio de seguir actuando en la investigación de aquellos delitos del orden militar que resulten de los mismos hechos.
\end{abstract}

Pero no solamente la policía militar o el ministerio público castrense que tenga conocimiento de un caso que no involucre la disciplina militar, deben de abstenerse de conocer este tipo de procesos o investigaciones, además las autoridades civiles que no deberán remitir a estas autoridades marciales la pesquisa o el juicio que no tenga relación con la disciplina militar, aún que los imputados o las víctimas sean militares.

Lo que implica es que, si el asunto llega al conocimiento de cualquiera de los órganos que lo conforman [la Procuraduría General de la República], los hechos

\footnotetext{
${ }^{9}$ Sin embargo, a la fecha el Estado mexicano ha dado cumplimiento parcial a su obligación de adoptar las reformas legislativas pertinentes para compatibilizar el artículo 57 del Código de Justicia Militar con los estándares internacionales en la materia y la Convención Americana sobre Derechos Humanos, de acuerdo con el punto dispositivo décimo de la Sentencia del caso RRP, el punto dispositivo décimo tercero de la Sentencia del caso Fernández Ortega y otros, y el punto dispositivo décimo segundo de la Sentencia del caso Rosendo Cantú y otra. (Casos Radilla Pacheco, Fernández Ortega y otros, y Rosendo Cantú y otra VS. México, 2015).
} 
investigados no pueden ser remitidos al fuero militar, ni debe serle reconocida competencia alguna al mencionado fuero. El asunto sólo puede ser conocido por las autoridades jurisdiccionales civiles. ${ }^{10}$

La jurisdicción diferente al juez natural es una violación al principio del juicio justo y el derecho a la debida defensa en el proceso.

\subsubsection{Juez natural integral}

En el Caso RRP la Corte IDH (2009) respecto al juez natural estableció:

[...] la sola posibilidad de que las decisiones emanadas de tribunales militares puedan ser "revisadas" por las autoridades federales no satisface el principio del juez natural, ya que desde la primera instancia el juez debe ser competente... los tribunales militares no son competentes para conocer de la detención y posterior desaparición forzada del señor Rosendo Radilla Pacheco (Párrafo 281).

El concepto del juez natural y el principio del debido proceso legal [...] se proyectan sobre las diversas instancias procesales. Si el juzgador de segunda instancia no satisface los requerimientos del juez natural, no podrá establecerse como legítima y válida la etapa procesal que se desarrolle ante él ${ }^{11}$.

\subsubsection{Juez natural integral. Disciplina militar.}

[...] la desaparición forzada del señor Rosendo Radilla Pacheco no guarda relación con la disciplina militar y que, por lo tanto, está excluido de la competencia de la jurisdicción castrense...la jurisdicción penal militar debe estar encaminada a la protección de intereses jurídicos especiales, vinculados con las funciones que la ley asigna a las fuerzas militares. Establecer lo contrario atentaría contra el principio del juez natural, a la luz del artículo 8.1 de la Convención Americana [...] (párrafo 300).

El Tribunal estima que al extender la competencia del fuero castrense a delitos que no tienen estricta conexión con la disciplina militar o con bienes jurídicos propios del ámbito castrense, el Estado ha vulnerado el derecho a un juez natural de los familiares del señor Rosendo Radilla Pacheco [...] (párrafo 313).

\subsubsection{Juez natural. Sanción a los responsables. Disciplina militar.}

\footnotetext{
${ }^{10}$ COSsío DíAZ, J. R., Algunas notas sobre el caso Rosedo Radilla Pacheco. Anuario Mexicano de Derecho Internacional, 2014, p. 25.

${ }^{11}$ Corte IDH. Casos Lori Berenson, párrafo 192, y Castillo Petruzzi y otros, párrafo 161.
} 
[...] la Corte considera que la investigación de la detención y posterior desaparición forzada del señor Rosendo Radilla Pacheco no ha sido diligente, no ha sido asumida en su totalidad como un deber propio del Estado ni ha estado dirigida eficazmente tanto a la identificación, proceso y eventual sanción de todos los responsables como a la determinación del paradero del señor Radilla Pacheco [...] (párrafo 313).

\section{RECURSO EFICAZ}

Los recursos ordinarios son medios de impugnación de las resoluciones judiciales previstos en la ley que regula específicamente un tipo de proceso, al que tienen derecho las partes, con la finalidad de que se estudie nuevamente el proveído fuente del disenso por otro órgano jurisdiccional o por el mismo tribunal que lo dictó, y se tenga la posibilidad real, en un plazo razonable de que sea revocado, modificado o anulado por ser contrario al derecho.

El hecho que se establezcan recursos ordinarios contra las resoluciones intermedias y contra la sentencia implica cumplir con el derecho humano vinculado al debido proceso y fortalece el sistema de justicia.

Los recursos transmiten la noción que el sistema no tiene flancos débiles asintiendo que dentro de su misma funcionalidad y estructuración puedan ser revisados los fallos de los magistrados de rango inferior. Se refuerza de esta manera el grado de certeza de las decisiones judiciales brindando una mayor seguridad jurídica. ${ }^{12}$

La CADH en el artículo 25, fracción I referente a la Protección Judicial prevé:

Toda persona tiene derecho a un recurso sencillo y rápido o a cualquier otro recurso efectivo, ante los jueces o tribunales competentes, que la ampare contra actos que violen sus derechos fundamentales reconocidos por la Constitución, la ley o la presente Convención, aun cuando tal violación sea cometida por personas que actúen en ejercicio de sus funciones oficiales.

\subsection{Características}

\footnotetext{
${ }^{12}$ VILLALBA BERNIÉ, Pablo Darío, Reflexiones sobre el Sistema Interamericano de Derechos Humanos: una visión crítica, revista jurídica Primera Instancia, México, número 5, 2015, Revista jurídica Primera Instancia, 2015, p. 32.
} 
Frente al yerro de la autoridad que en esencia representa una arbitrariedad el recurso ordinario en forma general debe reunir las características de sencillo, rápido y eficaz.

\subsection{1 ¿Qué significa que el recurso sea sencillo?}

De acuerdo con el Diccionario de la Real Academia de la Lengua Española, entre diversas acepciones la palabra sencillo significa: "que no ofrece dificultad".

[...] el Tribunal [Corte IDH] ha sostenido que el artículo 8.2 (h) de la CADH se refiere a un recurso ordinario accesible y eficaz, es decir que no debe requerir mayores complejidades que tornen ilusorio este derecho. En ese sentido, las formalidades requeridas para que el recurso sea admitido deben ser mínimas y no deben constituir un obstáculo para que el recurso cumpla con su fin de examinar y resolver los agravios sustentados por el recurrente, mejor dicho, debe procurar resultados o respuestas al fin para el cual fue concebido. ${ }^{13}$

\subsection{2 ¿Qué significa que el recurso sea eficaz?}

Que el recurso sea eficaz quiere decir que a través de este se pueda lograr el propósito, cumplir con el objetivo o propósito para la cual se reglamentó: evitar el error judicial, mejorar la administración de justicia y depurar el proceso ante cualquier falla a través de un nuevo estudio del caso.

[...] Debe entenderse que, independientemente del régimen o sistema recursivo que adopten los Estados Partes y de la denominación que den al medio de impugnación de la sentencia condenatoria, para que este sea eficaz debe constituir un medio adecuado para buscar la corrección de una condena errónea $[\ldots]^{14}$

\subsubsection{Recurso como derecho a la defensa}

La Corte IDH ha establecido que la existencia del recurso ordinario se relaciona con el derecho a la defensa:

a) Recurso ordinario: el derecho de interponer un recurso contra el fallo debe ser garantizado antes de que la sentencia adquiera la calidad de cosa juzgada, pues

\footnotetext{
${ }^{13}$ Corte IDH. Caso Liakat Ali Alibux Vs. Surinam, (Corte IDH. 30 de Enero de 2014, Párrafo 86).

${ }^{14}$ Ibídem, párrafo 86.
} 
busca proteger el derecho de defensa evitando que quede firme una decisión adoptada en un procedimiento viciado y que contenga errores que ocasionarán un perjuicio indebido a los intereses de una persona. ${ }^{15}$

\subsection{Recurso eficaz e idóneo}

No basta con que se incluya un recurso en la ley procesal, sino que éste debe lograr la finalidad para lo cual es legislado: un reestudio de la decisión por un órgano jurisdiccional imparcial de jerarquía mayor de quien emitió el proveído a revisar, y en caso de haber un error judicial, que este sea remediado en un plazo razonable, es decir, que sea eficaz, así se dijo en el Caso RRP:

En este sentido, el Tribunal ha establecido que para que el Estado cumpla lo dispuesto en el artículo 25 de la Convención no basta que los recursos existan formalmente, sino que es preciso que tengan efectividad en los términos de aquel precepto. La Corte ha reiterado que dicha obligación implica que el recurso sea idóneo para combatir la violación y que sea efectiva su aplicación por la autoridad competente (párrafo 296).

El juicio de amparo es de creación mexicana, data de 1841, pero no ha sido desarrollado de tal manera que sea un medio eficaz para restituir a las víctimas de violaciones de derechos humanos, todavía en la actualidad cada sentencia de amparo que determina que se han trasgredido derechos fundamentales, no ordena la reparación integral, la práctica judicial en el país es más tutelar de los órganos del Estado que de los seres humanos situación evidenciada en el Caso RRP:

[...] el recurso de amparo no fue efectivo para permitir a la señora Tita Radilla Martínez impugnar el conocimiento de la detención y posterior desaparición forzada de su padre, el señor Rosendo Radilla Pacheco, por la jurisdicción militar, lo cual constituye una violación del artículo 25.1 de la Convención (párrafo 298).

[Las víctimas] tampoco dispusieron de un recurso que les permitiera impugnar el juzgamiento de la detención y posterior desaparición forzada del señor Rosendo Radilla Pacheco por la jurisdicción militar. Todo ello en detrimento del derecho a conocer la verdad de aquéllos (párrafo 313).

Esta obligación generica procesal tiene su fuente en la Convención ADH como se estipuló en el Caso RRP:

\footnotetext{
${ }^{15}$ Ibíd., párrafo. 85
} 
La Corte ha considerado que el Estado está en la obligación de proveer recursos judiciales efectivos a las personas que aleguen ser víctimas de violaciones de derechos humanos (artículo 25), recursos que deben ser sustanciados de conformidad con las reglas del debido proceso legal (artículo 8.1), todo ello dentro de la obligación general, a cargo de los mismos Estados, de garantizar el libre y pleno ejercicio de los derechos reconocidos por la Convención a toda persona que se encuentre bajo su jurisdicción (artículo 1.1). (párrafo 119).

\subsection{Cumplimiento de la sentencia}

En este punto, la existencia de un recurso ordinario para cuestionar la jurisdicción militar, la Corte IDH al realizar en el 2015 de forma conjunta la supervisión de cuatro casos, determinó el cumplimiento total de la obligación, lo cual no significa que en forma integral se haya cumplido con el fallo, baste precisar que a la fecha se desconoce el paradero vivo o muerto de Rosendo Radilla Pacheco, y como se dijo, el amparo no es un medio hasta hoy en la práctica judicial totalmente eficaz sobre todo en lo que respecta a la reparación integral:

El Estado ha dado cumplimiento total a su obligación de adoptar las reformas pertinentes para permitir que las personas afectadas por la intervención del fuero militar cuenten con un recurso efectivo de impugnación de tal competencia, de acuerdo con los puntos dispositivos décimo cuarto de la Sentencia del caso Fernández Ortega y otros y décimo tercero de la Sentencia del caso Rosendo Cantú y otra. ${ }^{16}$

Los tribunales mexicanos han utilizado en su jurisprudencia la referencia al caso Radilla Pacheco en lo que corresponde al recurso eficaz:

Convención $\mathrm{ADH}$, aplicación de su artículo 25. El ordenamiento jurídico mexicano prevé como figuras de defensa respecto de los actos de las autoridades fiscales el recurso de revocación y el juicio contencioso administrativo federal, cuyo objeto es tutelar el derecho humano de protección judicial reconocido en dicho precepto. Según criterio interpretativo de la Corte Interamericana de Derechos Humanos, al cual los Jueces mexicanos pueden acudir en términos de lo considerado por el Pleno de la Suprema Corte de Justicia de la Nación al resolver el expediente varios 912/2010 (caso Radilla Pacheco), la obligación a cargo de los Estados miembros derivada del artículo 25 de la Convención Americana sobre Derechos Humanos, se traduce en prever la existencia de un recurso judicial accesible y efectivo contra actos que violen derechos fundamentales, lo que implica que el órgano dirimente previsto por el respectivo sistema legal decida sobre los derechos de toda persona que lo interponga y se garantice el

${ }^{16}$ Corte IDH. Casos Radilla Pacheco, Fernández Ortega y otros, y Rosendo Cantú y otra VS. México, Supervisión de cumplimiento (Corte IDH 17 de Abril de 2015). 
cumplimiento, por las autoridades competentes, de toda decisión en que se haya estimado procedente el recurso; es decir, el sentido de la protección otorgada por el artículo en cuestión consiste en la posibilidad real de acceder a un recurso judicial para que la autoridad competente y capaz de emitir una decisión vinculante determine si ha habido o no una violación a algún derecho que la persona que reclama estima tener y que, en caso de ser encontrada una violación, el recurso sea útil para restituir al interesado en el goce de su derecho y repararlo. En ese contexto, del análisis sistemático de los artículos 116, 117, 120, 125, 131, 132, 133 y 133-A del Código Fiscal de la Federación, 10., 2o. y 52 de la Ley Federal de Procedimiento Contencioso Administrativo, y 14 de la Ley Orgánica del Tribunal Federal de Justicia Fiscal y Administrativa, se desprende que el orden jurídico mexicano prevé como medios de defensa para impugnar las resoluciones de las autoridades fiscales, el recurso de revocación, en sede administrativa, y el juicio contencioso administrativo federal; ambos reúnen los requisitos de accesibilidad y efectividad, pues las hipótesis en que son procedentes están expresamente reguladas en los ordenamientos legales precisados (artículos 117 del Código Fiscal de la Federación, y 2o. de la Ley Federal de Procedimiento Contencioso Administrativo, este último en relación con el diverso 14 de la Ley Orgánica del Tribunal Federal de Justicia Fiscal y Administrativa); tienen el alcance jurídico de lograr la insubsistencia del acto controvertido (artículos 133, fracciones IV y V, del Código Fiscal de la Federación, y 52, fracciones II, III, IV y V, de la Ley Federal de Procedimiento Contencioso Administrativo); las resoluciones dictadas en ellos son vinculantes para las autoridades que emitieron el acto combatido (artículos 133-A, primer párrafo, del Código Fiscal de la Federación, y 52 de la Ley Federal de Procedimiento Contencioso Administrativo); y existen disposiciones tendentes a lograr el cumplimiento de aquéllas (artículos 133-A del Código Fiscal de la Federación, y 52, párrafos segundo a octavo, de la Ley Federal de Procedimiento Contencioso Administrativo). Con lo anterior, se constata que el Estado Mexicano ha implementado los mecanismos jurídicos necesarios para garantizar el derecho humano de protección judicial que tutela el artículo 25 de la Convención Americana sobre Derechos Humanos. ${ }^{17}$ (Subrayado añadido)

\section{CONTROL DIFUSO DE CONVENCIONALIDAD}

El control difuso de convencionalidad para los jueces de Latinoamérica implica un cambio de paradigma en la manera de comprender, aplicar e interpretar el derecho, un canje dinámico y extensivo, porque las normas convencionales penetraron en el derecho positivo de los Estados Parte, que por mucho tiempo se limitaron a desarrollar su actividad en un circuito jurídico cerrado, ahora se pretende romper los moldes positivistas cuando estos sean contrarios al objeto y fin de proteger efectivamente los derechos humanos.

La sentencia del Caso Radilla Pacheco es la primera resolución dictada en contra de México en la cual se vincula directamente al Poder Judicial de la Federación (PJF) al

\footnotetext{
17 Semanario Judicial de la Federación y su Gaceta, Tesis: VI.10.A. J/3 (10a.), Libro XV, diciembre de 2012, Tomo 2, p. 1116.
} 
cumplimiento de algunas medidas de reparación, así como que también por primera vez se hace mención en una sentencia dirigida al Estado mexicano del control de convencionalidad que deben ejercer los jueces y tribunales nacionales. ${ }^{18}$

El control difuso de convencionalidad es más complejo que se piensa. Además de hacer un parangón de normas internas respecto a la CADH, el juez local debe tener conocimientos sobre la jurisprudencia de la Corte IDH, así como conocer el corpus iuris del SIDH. La información actualizada de lo que acontece en el SIDH es requisito indispensable para cada juez local que quiera hacer valer los $\mathrm{DH} .{ }^{19}$

\subsection{Impacto ante la Suprema Corte de Justicia de la Nación}

La Suprema Corte de Justicia de la Nación (SCJN), el 14 de julio de 2011 al resolver la consulta a trámite, radicado en el Expediente Varios 912/2010, relativa al cumplimiento que el Poder Judicial de la Federación le daría a la sentencia del Caso RRP, ya que por primera vez un fallo interamericano determinó obligaciones a la judicatura nacional, así la SCJN fijó el criterio obligatorio para todas y todos los jueces del país de aplicar en sus sentencias el control difuso de convencionalidad.

Además, la SCJN dejó sin efecto las jurisprudencias que prohibían el llamado control difuso de constitucionalidad para que a partir de la sentencia de la Corte IDH los tribunales y juzgados ordinarios estén facultados para pronunciarse sobre la constitucionalidad y convencionalidad de leyes y normas secundarias.

\subsubsection{Referencias}

a) En 13 de julio de 1999, el Pleno de la SCJN aprobó dos jurisprudencias (P./J. 73/99 y 74/99) relativas al control de la Constitución Federal, contemplado en su artículo 133, en las que estableció que dicho precepto no permitía un control difuso de la constitucionalidad, es decir, que cualquier juzgador dejaría de aplicar en los casos concretos las normas jurídicas que a su consideración se opusieran a la Constitución Federal. Por lo anterior, estipuló que ese control debería ser concentrado y exclusivo del Poder Judicial de la Federación, y en consecuencia, era una facultad exclusiva del mismo.

\footnotetext{
${ }^{18}$ CASTILLA, K., El control de convencionalidad: Nuevo debate en México a partir de la sentencia del caso Radilla Pacheco. Anuario Mexicano de Derecho, 2011, p. 595.

${ }^{19}$ MARTíNEZ LAZCANO , A. J., \& CUBIDES CÁRDENAS, A. J., Op. Cit., p.97.
} 
b) En el mes de julio de 2001, la SCJN analizó la sentencia emitida en 23 de noviembre de 2009 por la Corte IDH en el caso 12.511 RRP contra los Estados Unidos Mexicanos, a fin de determinar si la sentencia contenía obligaciones a cargo del PJF.

Como resultado de lo anterior, la SCJN resolvió que los juzgadores de todo el país, incluidos los de los Estados y el Distrito Federal (hoy ciudad de México), están obligados, en los casos concretos que les toque resolver, a verificar que las leyes y en general todas las normas jurídicas aplicables sean conformes a la Constitución Federal y a los tratados internacionales sobre derechos humanos.

De darse el supuesto de que esas normas se opongan a la Constitución y a los tratados en derechos humanos, los jueces de todo el país deben dejar de aplicarlas en sus decisiones, sin que ello implique que dichas normas queden sin efectos de manera general, ya que esa facultad sí es exclusiva de la PJF.

Los criterios establecidos en 1999 son opuestos a lo resuelto en el Caso RRP, por lo que la SCJN inició un procedimiento en el que dejó sin efecto estas jurisprudencias.

\subsection{Control de convencionalidad. Efecto útil.}

Un elemento esencial del control difuso de convencionalidad es el efecto útil y tiene su origen en la Convención de Viena sobre Tratado al disponer la prohibición de invocar el derecho interno para desconocer el derecho convencional; así como las obligaciones previstas en la Convención $\mathrm{ADH}$, la primera de carácter positivo al agregar los derechos y libertades a los sistemas jurídicos de los Estados Parte, y otra de representación negativa, al erradicar cualquier práctica o disposición contraria a la Convención $\mathrm{ADH}$, así con independencia a que son los Estados Partes a través de sus agentes quienes son los primeros obligados a cumplir con el Pacto de San José y demás instrumentos interamericanos, y si no lo hacen es la Corte IDH la que tiene la última palabra sobre la interpretación y aplicación de las normas convencionales. Así se determinó en el Caso RRP:

En relación con las prácticas judiciales, este Tribunal ha establecido en su jurisprudencia que es consciente de que los jueces y tribunales internos están sujetos al imperio de la ley y, por ello, están obligados a aplicar las disposiciones vigentes en el ordenamiento jurídico. Pero cuando un Estado ha ratificado un tratado internacional como la Convención Americana, sus jueces como parte del aparato del Estado, también están sometidos a ella, lo que les obliga a velar porque los efectos de las disposiciones de la Convención no se vean mermados 
por la aplicación de leyes contrarias a su objeto y fin, que desde un inicio carecen de efectos jurídicos. En otras palabras, el Poder Judicial debe ejercer un "control de convencionalidad" ex officio entre las normas internas y la Convención Americana, evidentemente en el marco de sus respectivas competencias y de las regulaciones procesales correspondientes. En esta tarea el Poder Judicial debe tener en cuenta no solamente el tratado, sino también la interpretación que del mismo ha hecho la Corte Interamericana, intérprete última de la Convención Americana (Párrafo 339).

\section{CONCLUSIÓN}

1. El Caso RRP ocasionó una revolución jurídica en el ámbito interno de México;

2. La Corte IDH creó importante jurisprudencia vinculatoria para todos los Estados Parte del SIDH en el Caso RRP;

3. La jurisprudencia del Caso RRP versa sobre la justicia miliar: el juez natural, la disciplina militar; la exigencia de establecer en las normas procesales un recurso eficaz; sujetar las actuaciones del Estado al concepto del plazo razonable; la distinción entre las víctimas directas e indirectas; la forma de reparación integral; la violación de la integridad personal de familiares; sufrimiento de las víctimas; la integridad personal; el tipo de desaparición forzada de personas como delito continuo o permanente; el acceso al expediente durante la investigación; la obtención de copias de la averiguación previa por parte de las víctimas; el derecho a la verdad; el efecto útil de las normas convencionales; el control difuso de convencionalidad; el deber del Estado de realizar investigaciones serias y efectivas, entre otras para procesar y sancionar a los responsables de violar derechos humanos para combatir la impunidad;

4. La jurisdicción castrense está limitada a resolver cuestiones propias de la disciplina militar y a los bienes del ámbito castrense, ajena a cualquier tipo de proceso donde la litis ventile la violación a derechos humanos, sea la parte activa o pasiva, un civil o militar, la víctima o victimario, en este supuesto la competencia corresponde exclusivamente a los tribunales civiles, tampoco la policía militar debe intervenir en las investigaciones de esta índole, las cuales deben ser diligentes, serias y eficaces para lograr la identificación a los posibles responsables, procesarlos y dictar eventual sanción que corresponda.

5. El juicio de amparo es de creación mexicana y data de 1841 , pero no ha sido desarrollado de tal manera que sea un medio eficaz para restituir a las víctimas de la violación de derechos humanos, todavía en la actualidad cada sentencia de amparo en la que se determina que se han trasgredido derechos fundamentales no ordena la reparación integral, 
porque la práctica judicial en el país es más tutelar de los órganos del Estado que de los seres humanos y de la impunidad, situación evidenciada en el Caso RRP.

6. El control difuso de convencionalidad para los jueces de Latinoamérica implica un cambio de paradigma en la manera de comprender, aplicar e interpretar el derecho, un canje dinámico y extensivo, porque las normas convencionales penetraron en el derecho positivo de los Estados Parte que por mucho tiempo se limitaron a desarrollar su actividad en un circuito jurídico cerrado, ahora se pretende romper los moldes positivistas cuando éstos sean contrarios al objeto a fin de proteger efectivamente los derechos humanos.

7. Un elemento esencial del control difuso de convencionalidad es el efecto útil, que tiene su origen en la Convención de Viena sobre Tratados al disponer la prohibición de invocar el derecho interno para desconocer el derecho convencional; así como las obligaciones previstas en la Convención ADH.

\section{REFERENCIAS}

\section{Doctrina:}

CASTILLA, K.. El control de convencionalidad: Nuevo debate en México a partir de la sentencia del caso Radilla Pacheco. Anuario Mexicano de Derecho, 2011.

COSSío DíAZ, José. R., Algunas notas sobre el caso Rosendo Radilla Pacheco. Anuario Mexicano de Derecho Internacional, México, 2014.

FERNÁNDEZ GONZÁLEZ, Miguel Ángel, Derecho a la jurisdicción y debido proceso. Estudios Constitucionales [en linea] 2, 2004. Disponible en: <http: / / www.redalyc.org/articulo.oa?id=82020103> . Acesso em: 15 maio 2017. ISSN 07180195.

FLORES-GARCÍA, F. Jurisdicción. Diccionario Jurídico Mexicano, Porrúa, México, 1992.

MARTÍNEZ LAZCANO , A. J., \& Cubides Cárdenas, A. J. Influencia de la Corte Interamericana de Derechos Humanos y el control de convencionalidad: Análisis de dos casos paradigmáticos.

Eficacia del Sistema Interamericano de Derechos Humanos, Colección Jus Universidad Católica de Colombia, Bogotá, 2015.

QUISPE REMÓN , F. El derecho al juez natural -como derecho humano- y los tribunales militares en Colombia. Eunomía. Revista en Cultura de la Legalidad, Bogotá, 2013.

ROSALES GUERRERO, E. G., Estudio sistemático de la jurisprudencia. México: SCJN, 2005. 
VILLALBA BERNIÉ, Pablo Darío, Reflexiones sobre el Sistema Interamericano de Derechos Humanos: una visión crítica, revista jurídica Primera Instancia, número 5, Revista jurídica Primera Instancia, 2015.

2. Jurisprudencia:

Corte IDH. Caso Escué Zapata Vs. Colombia. (4 de julio de 2007).

Corte IDH. Caso Liakat Ali Alibux Vs. Surinam (30 de enero de 2014).

Corte IDH. Caso Radilla Pachecho vs Estados Unidos Mexicanos (23 de noviembre de 2009).

Corte IDH. Casos Radilla Pacheco, Fernández Ortega y otros, y Rosendo Cantú y otra VS. México, Supervisión de cumplimiento (17 de abril de 2015).

Corte IDH. Supervisión del Caso Gelman Vs. Uruguay (20 de marzo de 2013 ).

Semanario Judicial de la Federación y su Gaceta, Tesis: VI.10.A. J/3 (10a.), Libro XV, diciembre de 2012, Tomo 2, p. 1116.

\section{COMO FAZER A REFERÊNCIA DO ARTIGO (ABNT):}

LAZCANO, Alfonso Jaime Martínez. Jurisprudencia de la Corte Interamericana de Derechos Humanos: caso Rosendo Radilla Pacheco. Revista Eletrônica do Curso de Direito da UFSM, Santa Maria, RS, v. 12, n. 3, p. 1068-1084, dez. 2017. ISSN 1981-3694.

Disponível em: <https://periodicos.ufsm.br/revistadireito/article/view/30485>. Acesso em: dia mês. ano.

doi:http://dx.doi.org/10.5902/1981369430485. 